\title{
Synthesis and SARS-CoV-2 3CL Protease Inhibitory Effects of Oxazolidinone Derivatives
}

\author{
Shengxian Zhao, ${ }^{\circledR \#, a}$ Chaojie Wang, ${ }^{\#, b}$ Yiming $\mathbf{L u},{ }^{a}$ Xin Zhang, ${ }^{a}$ Siyu $W u^{a}$ and \\ $\mathrm{Hui} \mathrm{Mao}^{*, a, c}$ \\ ${ }^{a}$ College of Science and Technology, Ningbo University, 315302 Cixi, China \\ ${ }^{b}$ School of Pharmaceutical Sciences, Xiamen University, South Xiang-An Road, \\ 361102 Xiamen, China \\ ${ }^{c}$ College of Pharmaceutics, Jinhua Polytechnic, 321007 Jinhua, China
}

The 3-chymotrypsin-like protease $\left(3 \mathrm{CL}^{\text {pro }}\right)$ is an attractive target for the development of anti-SARS (severe acute respiratory syndrome) drugs. In this work, a series of oxazolidinone derivatives $\mathbf{3 a - 3 v}$ were synthesized and their inhibitory activities against SARS coronavirus 2 (SARS-CoV-2) $3 \mathrm{CL}^{\text {pro }}$ were evaluated by the fluorescence resonance energy transfer (FRET)-based enzymatic assay. Among synthesized compounds, $\mathbf{3 g}$ displayed the best inhibitory activity, with a half maximal inhibitory concentration $\left(\mathrm{IC}_{50}\right)$ value of $14.47 \mu \mathrm{M}$. Also, docking studies implied that compound $3 \mathrm{~g}$ was fitted into the active pocket of $3 \mathrm{CL}^{\text {pro }}$, forming a hydrogen bond with Glu 166 .

Keywords: oxazolidinones, SARS-CoV-2, 3CL protease, inhibitory activity

\section{Introduction}

Since the isolation of the first human coronavirus in $1965,{ }^{1,2}$ seven family members have been identified. ${ }^{3}$ Three of them, severe acute respiratory syndrome coronavirus (SARS-CoV), Middle East respiratory syndrome coronavirus (MERS-CoV) and severe acute respiratory syndrome coronavirus 2 (SARS-CoV-2) have caused very severe respiratory diseases in humans over the past 20 years..$^{2-5}$ The coronavirus disease 2019 (COVID-19) outbreak has taken a large number of human deaths and severe economic losses globally. ${ }^{6,7}$ This virus is most likely to coexist with humans for a long time, ${ }^{8}$ so there is an urgent demand to develop preventive and therapeutic measures. From what has been reported so far, ${ }^{9}$ the vaccine may not be effective enough due to the mutation of the virus. In the meantime, no specific antiviral drugs are currently available for the prevention and treatment of COVID-19 infections. ${ }^{10}$

After coronavirus infection, its genetic material RNA (ribonucleic acid) first encodes into two polymeric

*e-mail: maohui1988@126.com

"These authors contributed equally to the work.

Editor handled this article: Brenno A. D. Neto (Associate) precursors pp1a and pp1ab. Under the action of 3 -chymotrypsin-like protease $\left(3 \mathrm{CL}^{\text {pro }}\right)$ and papain-like protease $\left(\mathrm{PL}^{\mathrm{pro}}\right)$, the polymeric precursors undergo intramolecular cleavage to produce multiple non-structural proteins. Because the $3 \mathrm{CL}$ protease is responsible for cutting at least 11 sites and is extremely important for virus replication, it is also called the main protease $\left(\mathrm{M}^{\mathrm{pro}}\right)$, and this protease has no homologous protein in the human body. ${ }^{11,12}$ Gene sequence analysis showed that this protease is relatively conserved, and the $3 \mathrm{CL}$ proteases of SARS$\mathrm{CoV}$ and SARS-CoV-2 are highly similar on the gene sequences and active site. ${ }^{13}$ Therefore, $3 \mathrm{CL}^{\text {pro }}$ is an ideal target for the development of anti-coronavirus drug.

The coronavirus $3 \mathrm{CL}^{\text {pro }}$ inhibitors reported in the literature are mainly divided into peptide inhibitors ${ }^{12-18}$ and non-peptide inhibitors. ${ }^{19-22}$ Commonly non-peptide inhibitors belong to reversible inhibitors, which compete for the active site of protease with natural substrates. The oxazolidinone derivatives have shown antibacterial, ${ }^{23}$ anticoagulant, ${ }^{24}$ and cholesteryl ester transfer protein inhibiting activity. ${ }^{25}$ Linezolid, tedizolid, rivaroxaban, anacetrapib, and other oxazolidinone derivatives have been on the market for many years, as the safety profile has been proved. The sulfonamide hybrided oxazolidinones displayed excellent activities toward 


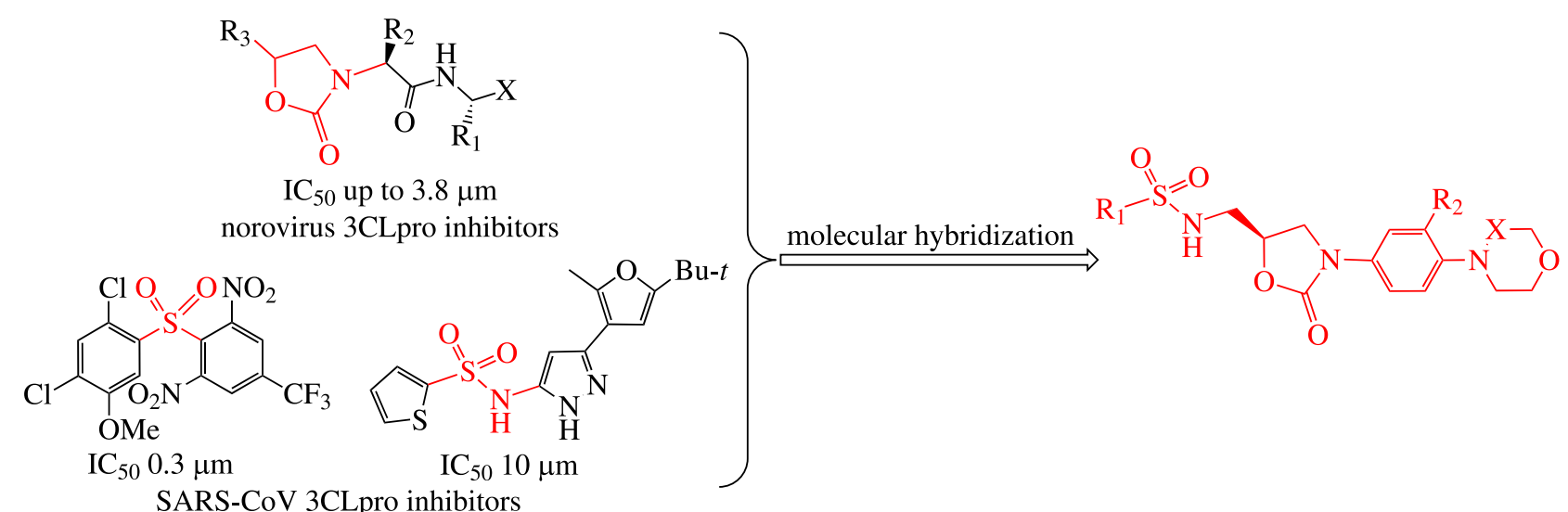

Figure 1. Design of target compounds 3a-3v.

human immunodeficiency virus-1 (HIV-1) protease and significant antiviral activities. ${ }^{26}$ Further, the oxazolidinone ring was designed as a novel design element for the binding interaction with active sites of norovirus $3 \mathrm{CL}^{\text {pro }} .{ }^{27} \mathrm{On}$ the other hand, the aryl sulfones and sulfonamides showed the inhibitory activities against SARS-CoV $3 \mathrm{CL}^{\text {pro }} .{ }^{28}$ Hence, target compounds $\mathbf{3 a - 3 v}$ (Figure 1) were designed as possible inhibitors of $3 \mathrm{CL}^{\text {pro }}$ and docking analysis demonstrated that these compounds had a moderate binding affinity with $3 \mathrm{CL}^{\text {pro }}$. Herein, we report the identification of $\mathbf{3 g}$ as a novel inhibitor of SARS-CoV-2 3CL protease.

\section{Experimental}

\section{Chemistry}

\section{Materials and methods}

All chemicals were analytically pure and purchased from Shanghai Baishun Biotechnology Co., Ltd. (Shanghai, China). All melting points were determined on a WRS-1B Digital Melting Point Apparatus (uncorrected, Shanghai Precision Instruments Co., Ltd., Shanghai, China). All new compounds were characterized by ${ }^{1} \mathrm{H}$ nuclear magnetic resonance (NMR), ${ }^{13} \mathrm{C}$ NMR, and high-resolution mass spectrometry (HRMS). NMR spectra were recorded in dimethyl sulfoxide (DMSO- $d_{6}$ ) on a Bruker Avance Neo $500 \mathrm{MHz}$ instrument (Fällanden, Switzerland). HRMS spectra were obtained on an Agilent 1290II+6545 mass spectrometer (Waldbronn, Germany).

General procedure for the synthesis of target compounds $\mathbf{3 a}-\mathbf{3 v}$

To a solution of sulfonyl chloride $(1 \mathrm{mmol})$ and amine $(1 \mathrm{mmol})$ in dichloromethane $(12 \mathrm{~mL})$ was added triethylamine $(1.2 \mathrm{mmol}, 0.1214 \mathrm{~g})$. The mixture was stirred at room temperature for $5 \mathrm{~h}$, and monitored by thin layer chromatography (TLC, ethyl acetate: $n$-hexane 2:1). After completion of the reaction, the mixture was washed three times with water, dried over anhydrous sodium sulfate, and purified by column chromatography (ethyl acetate: $n$-hexane 2:1) to obtain the products $\mathbf{3 a - 3 v}$.

(R)-N-((3-(3-Fluoro-4-morpholinophenyl)-2-oxooxazolidin5 -yl)methyl)benzenesulfonamide (3a)

White solid, yield: $92 \%$; mp 157.8-159.3 ${ }^{\circ} \mathrm{C}$; ${ }^{1} \mathrm{H}$ NMR $\left(500 \mathrm{MHz}, \mathrm{DMSO}-d_{6}\right) \delta 8.15(\mathrm{t}, J 7.5 \mathrm{~Hz}, 1 \mathrm{H}), 7.84-7.82$ (m, 2H), 7.68-7.64 (m, 3H), 7.49 (dd, J 2.5, $15.0 \mathrm{~Hz}, 1 \mathrm{H})$, 7.16 (dd, $J 2.1,15.0 \mathrm{~Hz}, 1 \mathrm{H}), 7.07$ (t, $J 10.0 \mathrm{~Hz}, 1 \mathrm{H}$ ), 4.73-4.69 (m, 1H), $4.08(\mathrm{t}, J 10.0 \mathrm{~Hz}, 1 \mathrm{H}), 3.78-3.73(\mathrm{~m}$, 5H), 3.16-3.06 (m, 2H), 2.97-2.95 (m, 4H); ${ }^{13} \mathrm{C}$ NMR $\left(125 \mathrm{MHz}, \mathrm{DMSO}-d_{6}\right) \delta 154.6(\mathrm{~d}, J 242.5 \mathrm{~Hz}), 153.9$, $140.3,135.6(\mathrm{~d}, J 8.8 \mathrm{~Hz}), 133.4(\mathrm{~d}, J 10.0 \mathrm{~Hz}), 132.6$, $129.3,126.5,119.3(\mathrm{~d}, J 3.8 \mathrm{~Hz}), 114.1(\mathrm{~d}, J 3.8 \mathrm{~Hz})$, $106.6(\mathrm{~d}, J 26.3 \mathrm{~Hz}), 71.2,66.2,50.7$ (d, $J 2.5 \mathrm{~Hz}), 46.9$, 45.2; HRMS (electrospray ionization (ESI)) $\mathrm{m} / \mathrm{z}$, calculated for $\mathrm{C}_{20} \mathrm{H}_{23} \mathrm{FN}_{3} \mathrm{O}_{5} \mathrm{~S}[\mathrm{M}+\mathrm{H}]^{+}:$436.1337, found: 436.1342; $\Delta 1.1 \mathrm{ppm}$.

(R)-N-((3-(3-Fluoro-4-morpholinophenyl)-2-oxooxazolidin5-yl)methyl)-4-methylbenzenesulfonamide (3b)

Off-white solid, yield: $78 \%$; mp 149.4-150.0 ${ }^{\circ} \mathrm{C}$; ${ }^{1} \mathrm{H}$ NMR $\left(500 \mathrm{MHz}\right.$, DMSO- $\left.d_{6}\right) \delta 8.05(\mathrm{t}, J 7.5 \mathrm{~Hz}, 1 \mathrm{H})$, $7.70(\mathrm{~d}, J 10.0 \mathrm{~Hz}, 2 \mathrm{H}), 7.48(\mathrm{dt}, J 1.1,15.0 \mathrm{~Hz}, 1 \mathrm{H}), 7.40$ (d, J $10.0 \mathrm{~Hz}, 2 \mathrm{H}), 7.16(\mathrm{dd}, J 5.0,10.0 \mathrm{~Hz}, 1 \mathrm{H}), 7.07$ (t, $J 10.0 \mathrm{~Hz}, 1 \mathrm{H}), 4.72-4.67(\mathrm{~m}, 1 \mathrm{H}), 4.08-4.01(\mathrm{~m}, 1 \mathrm{H})$, 3.75-3.73 (m, 5H), 3.13-3.03 (m, 2H), $2.96(\mathrm{t}, J 5.0 \mathrm{~Hz}$, $4 \mathrm{H}), 2.38$ (s, 3H); ${ }^{13} \mathrm{C}$ NMR (125 MHz, DMSO- $d_{6}$ ) $\delta 154.6$ (d, $J 242.5 \mathrm{~Hz}), 153.9,142.9,137.5,135.6(\mathrm{~d}, J 8.8 \mathrm{~Hz})$, $133.4(\mathrm{~d}, J 10.0 \mathrm{~Hz}), 129.7,126.5,119.3(\mathrm{~d}, J 3.8 \mathrm{~Hz})$, 114.1 (d, $J 2.5 \mathrm{~Hz}), 106.6$ (d, $J 25.0 \mathrm{~Hz}), 71.2,66.2,50.7$ (d, $J 2.5 \mathrm{~Hz}$ ), 46.9, 45.1, 21.0; HRMS (ESI) $\mathrm{m} / z$, calculated for $\mathrm{C}_{21} \mathrm{H}_{25} \mathrm{FN}_{3} \mathrm{O}_{5} \mathrm{~S}[\mathrm{M}+\mathrm{H}]^{+}:$450.1493, found: 450.1497; $\Delta 0.9 \mathrm{ppm}$. 
(R)-N-((3-(3-Fluoro-4-morpholinophenyl)-2-oxooxazolidin5-yl)methyl)-4-methoxybenzenesulfonamide (3c)

White solid, yield: $93 \%$; mp 174.2-175.7 ${ }^{\circ} \mathrm{C} ;{ }^{1} \mathrm{H}$ NMR $\left(500 \mathrm{MHz}, \mathrm{DMSO}-d_{6}\right) \delta 7.97(\mathrm{t}, J 5.0 \mathrm{~Hz}, 1 \mathrm{H}), 7.77-7.74$ (m, 2H), $7.48(\mathrm{dd}, J 2.5,15.0 \mathrm{~Hz}, 1 \mathrm{H}), 7.17-7.05(\mathrm{~m}, 4 \mathrm{H})$, 4.73-4.68 (m, 1H), $4.07(\mathrm{t}, J 10.0 \mathrm{~Hz}, 1 \mathrm{H}), 3.84(\mathrm{~s}, 3 \mathrm{H})$, 3.77-3.73 (m, 5H), 3.12-3.02 (m, 2H), $2.96(\mathrm{t}, J 5.0 \mathrm{~Hz}$, $4 \mathrm{H}) ;{ }^{13} \mathrm{C}$ NMR (125 MHz, DMSO- $\left.d_{6}\right) \delta 162.3,154.6(\mathrm{~d}$, $J 242.5 \mathrm{~Hz}), 154.0,135.6(\mathrm{~d}, J 8.8 \mathrm{~Hz}), 133.4(\mathrm{~d}, J 10.0 \mathrm{~Hz})$, 132.0, 128.7, $119.3(\mathrm{~d}, J 3.8 \mathrm{~Hz}), 114.4,114.1$ (d, J2.5 Hz), 106.6 (d, J 26.3 Hz), 71.2, 66.2, 55.7, 50.7 (d, J 3.8 Hz), $46.8,45.1$; HRMS (ESI) $m / z$, calculated for $\mathrm{C}_{21} \mathrm{H}_{25} \mathrm{FN}_{3} \mathrm{O}_{6} \mathrm{~S}$ $[\mathrm{M}+\mathrm{H}]^{+}:$466.1443, found: 466.1448; $\Delta 1.1 \mathrm{ppm}$.

(R)-4-Fluoro-N-((3-(3-fluoro-4-morpholinophenyl)-2-oxooxazolidin-5-yl)methyl)benzenesulfonamide (3d)

White solid, yield: 79\%; mp 168.0-168.8 ${ }^{\circ} \mathrm{C} ;{ }^{1} \mathrm{H}$ NMR $\left(500 \mathrm{MHz}, \mathrm{DMSO}-d_{6}\right) \delta 8.18(\mathrm{t}, J 5.0 \mathrm{~Hz}, 1 \mathrm{H}), 7.90-7.87$ $(\mathrm{m}, 2 \mathrm{H}), 7.50-7.42(\mathrm{~m}, 3 \mathrm{H}), 7.16(\mathrm{dd}, J 5.0,10.0 \mathrm{~Hz}$, $1 \mathrm{H}), 7.07(\mathrm{t}, J 10.0 \mathrm{~Hz}, 1 \mathrm{H}), 4.74-4.68(\mathrm{~m}, 1 \mathrm{H}), 4.08(\mathrm{t}$, $J 10.0 \mathrm{~Hz}, 1 \mathrm{H}), 3.76-3.73(\mathrm{~m}, 5 \mathrm{H}), 3.18-3.07(\mathrm{~m}, 2 \mathrm{H}), 2.97$ $(\mathrm{t}, J 5.0 \mathrm{~Hz}, 4 \mathrm{H}) ;{ }^{13} \mathrm{C}$ NMR (125 MHz, DMSO- $\left.d_{6}\right) \delta 164.2$ $(\mathrm{d}, J 248.8 \mathrm{~Hz}), 154.6(\mathrm{~d}, J 242.5 \mathrm{~Hz}), 153.9,136.8(\mathrm{~d}$, $J 3.8 \mathrm{~Hz}), 135.6$ (d, J $8.8 \mathrm{~Hz}), 133.3$ (d, J $11.3 \mathrm{~Hz}), 129.5$ (d, J $8.8 \mathrm{~Hz}), 119.3$ (d, J $3.8 \mathrm{~Hz}), 116.4$ (d, J 22.5 Hz), 114.1 (d, J 2.5 Hz), 106.6 (d, J 25.0 Hz), 71.2, 66.2, 50.7 (d, $J 2.5 \mathrm{~Hz}$ ), 46.9, 45.2; HRMS (ESI) $\mathrm{m} / z$, calculated for $\mathrm{C}_{20} \mathrm{H}_{22} \mathrm{~F}_{2} \mathrm{~N}_{3} \mathrm{O}_{5} \mathrm{~S}[\mathrm{M}+\mathrm{H}]^{+}:$454.1243, found: 454.1248; $\Delta 1.1 \mathrm{ppm}$.

(R)-4-Chloro- $N$-((3-(3-fluoro-4-morpholinophenyl)-2-oxooxazolidin-5-yl)methyl)benzenesulfonamide (3e)

White solid, yield: 88\%; mp 181.2-182.9 ${ }^{\circ} \mathrm{C} ;{ }^{1} \mathrm{H}$ NMR $\left(500 \mathrm{MHz}, \mathrm{DMSO}-d_{6}\right) \delta 8.25(\mathrm{t}, J 5.0 \mathrm{~Hz}, 1 \mathrm{H}), 7.84-7.81$ $(\mathrm{m}, 2 \mathrm{H}), 7.69-7.66(\mathrm{~m}, 2 \mathrm{H}), 7.48(\mathrm{dd}, J 5.0,15.0 \mathrm{~Hz}, 1 \mathrm{H})$, 7.15 (dd, J 2.2, 8.8 Hz, 1H), 7.07 (t, J7.5 Hz, 1H), 4.71-4.68 $(\mathrm{m}, 1 \mathrm{H}), 4.08(\mathrm{t}, J 10.0 \mathrm{~Hz}, 1 \mathrm{H}), 3.75-3.72(\mathrm{~m}, 5 \mathrm{H}), 3.20-$ $3.09(\mathrm{~m}, 2 \mathrm{H}), 2.96(\mathrm{t}, J 4.6 \mathrm{~Hz}, 4 \mathrm{H}) ;{ }^{13} \mathrm{C} \mathrm{NMR}(125 \mathrm{MHz}$, DMSO- $\left.d_{6}\right) \delta 154.6(\mathrm{~d}, J 242.5 \mathrm{~Hz}), 153.9,139.3,137.5$, $135.6(\mathrm{~d}, J 8.8 \mathrm{~Hz}), 133.3(\mathrm{~d}, J 11.3 \mathrm{~Hz}), 129.5,128.5,119.3$ (d, $J 3.8 \mathrm{~Hz}), 114.1$ (d, J $3.8 \mathrm{~Hz}), 106.6$ (d, J 26.3 Hz), 71.2, 66.2, 50.7 (d, J 3.8 Hz), 46.9, 45.2; HRMS (ESI) $m / z$, calculated for $\mathrm{C}_{20} \mathrm{H}_{22} \mathrm{ClFN}_{3} \mathrm{O}_{5} \mathrm{~S}[\mathrm{M}+\mathrm{H}]^{+}: 470.0947$, found: $470.0951 ; \Delta 0.9 \mathrm{ppm}$.

(R)-N-((3-(3-Fluoro-4-morpholinophenyl)-2-oxooxazolidin5-yl)methyl)-4-(trifluoromethyl)benzenesulfonamide (3f)

White solid, yield: 91\%; mp 179.7-181.6 ${ }^{\circ} \mathrm{C}$; ${ }^{1} \mathrm{H}$ NMR $\left(500 \mathrm{MHz}, \mathrm{DMSO}-d_{6}\right) \delta 8.42(\mathrm{t}, J 5.0 \mathrm{~Hz}, 1 \mathrm{H}), 8.01(\mathrm{dd}$, $J$ 7.5, 22.5 Hz, 4H), 7.49-7.46 (m, 1H), 7.15 (dd, J 5.0, $10.0 \mathrm{~Hz}, 1 \mathrm{H}), 7.07$ (t, J 7.5 Hz, 1H), 4.74-4.69 (m, 1H),
4.10-4.01 (m, 1H), 3.75-3.72 (m, 5H), 3.24-3.13 (m, 2H), $2.96(\mathrm{t}, J 2.5 \mathrm{~Hz}, 4 \mathrm{H}) ;{ }^{13} \mathrm{C}$ NMR $\left(125 \mathrm{MHz}, \mathrm{DMSO}-d_{6}\right)$ $\delta 154.6(\mathrm{~d}, J 242.5 \mathrm{~Hz}), 153.8,144.4,135.6$ (d, $J 8.8 \mathrm{~Hz})$, 133.3 (d, $J 11.3 \mathrm{~Hz}), 132.3$ (q, $J 32.5 \mathrm{~Hz}), 127.5,126.5$ (q, $J 3.8 \mathrm{~Hz}), 123.5(\mathrm{q}, J 267.5 \mathrm{~Hz}), 119.3(\mathrm{~d}, J 5.0 \mathrm{~Hz})$, 114.0 (d, J 2.5 Hz), 106.6 (d, J 26.3 Hz), 71.2, 66.2, 50.7 (d, J 2.5 Hz), 46.8, 45.2; HRMS (ESI) $\mathrm{m} / z$, calculated for $\mathrm{C}_{21} \mathrm{H}_{22} \mathrm{~F}_{4} \mathrm{~N}_{3} \mathrm{O}_{5} \mathrm{~S}[\mathrm{M}+\mathrm{H}]^{+}:$504.1211, found: 504.1216; $\Delta 1.0 \mathrm{ppm}$.

(R)-3-Fluoro- $N$-((3-(3-fluoro-4-morpholinophenyl)-2-oxooxazolidin-5-yl)methyl)benzenesulfonamide (3g)

White solid, yield: 94\%; mp 166.4-166.8 ${ }^{\circ} \mathrm{C} ;{ }^{1} \mathrm{H}$ NMR $\left(500 \mathrm{MHz}, \mathrm{DMSO}-d_{6}\right) \delta 8.27(\mathrm{t}, J 7.5 \mathrm{~Hz}, 1 \mathrm{H}), 7.70-7.61$ $(\mathrm{m}, 3 \mathrm{H}), 7.56-7.51(\mathrm{~m}, 1 \mathrm{H}), 7.48(\mathrm{dd}, J 5.0,15.0 \mathrm{~Hz}, 1 \mathrm{H})$, $7.16(\mathrm{dd}, J 5.0,10.0 \mathrm{~Hz}, 1 \mathrm{H}), 7.07$ (t, J $10.0 \mathrm{~Hz}, 1 \mathrm{H})$, 4.74-4.69 (m, 1H), 4.08 (t, J 10.0 Hz, 1H), 3.76-3.73 (m, $5 \mathrm{H}), 3.22-3.11(\mathrm{~m}, 2 \mathrm{H}), 2.97(\mathrm{t}, J 5.0 \mathrm{~Hz}, 4 \mathrm{H}) ;{ }^{13} \mathrm{C} \mathrm{NMR}$ $\left(125 \mathrm{MHz}, \mathrm{DMSO}-d_{6}\right) \delta 161.8(\mathrm{~d}, J 246.3 \mathrm{~Hz}), 154.6$ (d, $J 242.5 \mathrm{~Hz}), 153.9,142.5(\mathrm{~d}, J 6.3 \mathrm{~Hz}), 135.6(\mathrm{~d}, J 8.8 \mathrm{~Hz})$, $133.3(\mathrm{~d}, J 11.3 \mathrm{~Hz}), 131.7$ (d, J 7.5 Hz), 122.7 (d, J3.8 Hz), $119.8(\mathrm{~d}, J 20.0 \mathrm{~Hz}), 119.3(\mathrm{~d}, J 3.8 \mathrm{~Hz}), 114.1$ (d, J2.5 Hz), 113.6 (d, $J 23.8 \mathrm{~Hz}), 106.6$ (d, J 26.3 Hz), 71.2, 66.2, 50.7 (d, J 2.5 Hz), 46.9, 45.2; HRMS (ESI) $\mathrm{m} / z$, calculated for $\mathrm{C}_{20} \mathrm{H}_{22} \mathrm{~F}_{2} \mathrm{~N}_{3} \mathrm{O}_{5} \mathrm{~S}[\mathrm{M}+\mathrm{H}]^{+}:$454.1243, found: 454.1247; $\Delta 0.9$ ppm.

(R)-N-((3-(3-Fluoro-4-morpholinophenyl)-2-oxooxazolidin5-yl)methyl)-3-(trifluoromethyl)benzenesulfonamide (3h)

White solid, yield: $76 \%$; mp 137.8-138. ${ }^{\circ} \mathrm{C} ;{ }^{1} \mathrm{H}$ NMR $\left(500 \mathrm{MHz}, \mathrm{DMSO}-d_{6}\right) \delta 8.38(\mathrm{t}, J 7.5 \mathrm{~Hz}, 1 \mathrm{H}), 8.13(\mathrm{t}$, $J 10.0 \mathrm{~Hz}, 2 \mathrm{H}), 8.06(\mathrm{~d}, J 5.0 \mathrm{~Hz}, 1 \mathrm{H}), 7.87(\mathrm{t}, J 7.5 \mathrm{~Hz}$, 1H), 7.48 (dd, J 2.5, 15.0 Hz, 1H), 7.15 (dd, J 2.2, 8.8 Hz, $1 \mathrm{H}), 7.07(\mathrm{t}, J 10.0 \mathrm{~Hz}, 1 \mathrm{H}), 4.74-4.69(\mathrm{~m}, 1 \mathrm{H}), 4.08(\mathrm{t}$, $J 7.5 \mathrm{~Hz}, 1 \mathrm{H}), 3.75-3.72(\mathrm{~m}, 5 \mathrm{H}), 3.24-3.13(\mathrm{~m}, 2 \mathrm{H}), 2.96$ $(\mathrm{t}, J 4.6 \mathrm{~Hz}, 4 \mathrm{H}) ;{ }^{13} \mathrm{C}$ NMR $\left(125 \mathrm{MHz}, \mathrm{DMSO}-d_{6}\right) \delta 154.6$ $(\mathrm{d}, J 242.5 \mathrm{~Hz}), 153.9,141.7,135.6(\mathrm{~d}, J 8.8 \mathrm{~Hz}), 133.3$ (d, $J 11.3 \mathrm{~Hz}), 131.0,130.6,130.0$ (q, J 32.5 Hz), 129.4 $(\mathrm{q}, J 15.0 \mathrm{~Hz}), 123.5(\mathrm{q}, J 271.3 \mathrm{~Hz}), 123.1(\mathrm{q}, J 3.8 \mathrm{~Hz})$, $119.3(\mathrm{~d}, J 3.8 \mathrm{~Hz}), 114.1$ (d, J 2.5 Hz), 106.6 (d, J 26.3 Hz), 71.2, 66.2, 50.7 (d, J 2.5 Hz), 46.9, 45.2; HRMS (ESI) $\mathrm{m} / z$, for $\mathrm{C}_{21} \mathrm{H}_{22} \mathrm{~F}_{4} \mathrm{~N}_{3} \mathrm{O}_{5} \mathrm{~S}[\mathrm{M}+\mathrm{H}]^{+}:$504.1211, found: 504.1215; $\Delta 0.8 \mathrm{ppm}$.

(R)-N-((3-(3-Fluoro-4-morpholinophenyl)-2-oxooxazolidin5-yl)methyl)-3-nitrobenzenesulfonamide (3i)

Yellow solid, yield: $89 \%$; mp 179.3-179.7 ${ }^{\circ} \mathrm{C}$; ${ }^{1} \mathrm{H}$ NMR $\left(500 \mathrm{MHz}, \mathrm{DMSO}-d_{6}\right) \delta$ 8.56-8.46 (m, 3H), 8.24-8.22 $(\mathrm{m}, 1 \mathrm{H}), 7.90(\mathrm{t}, J 7.5 \mathrm{~Hz}, 1 \mathrm{H}), 7.45(\mathrm{dd}, J 5.0,15.0 \mathrm{~Hz}$, $1 \mathrm{H}), 7.13(\mathrm{dd}, J 5.0,10.0 \mathrm{~Hz}, 1 \mathrm{H}), 7.05(\mathrm{t}, J 7.5 \mathrm{~Hz}, 1 \mathrm{H})$, 4.74-4.69 (m, 1H), 4.07 (t, J 7.5 Hz, 1H), 3.75-3.70 (m, 
5H), 3.28-3.17 (m, 2H), $2.96(\mathrm{t}, J 5.0 \mathrm{~Hz}, 4 \mathrm{H}) ;{ }^{13} \mathrm{C} \mathrm{NMR}$ $\left(125 \mathrm{MHz}, \mathrm{DMSO}-d_{6}\right) \delta 154.6(\mathrm{~d}, J 242.5 \mathrm{~Hz}), 153.8$, 148.0, 142.1, 135.6 (d, $J 8.8 \mathrm{~Hz}), 133.3(\mathrm{~d}, J 10.0 \mathrm{~Hz})$, $132.5,131.4,127.2,121.4,119.3(\mathrm{~d}, J 5.0 \mathrm{~Hz}), 114.0$ $(\mathrm{d}, J 3.8 \mathrm{~Hz}), 106.6(\mathrm{~d}, J 26.3 \mathrm{~Hz}), 71.1,66.2,50.7$ (d, $J 2.5 \mathrm{~Hz}$ ), 46.9, 45.2; HRMS (ESI) $\mathrm{m} / \mathrm{z}$, calculated for $\mathrm{C}_{20} \mathrm{H}_{22} \mathrm{FN}_{4} \mathrm{O}_{7} \mathrm{~S}[\mathrm{M}+\mathrm{H}]^{+}:$481.1188, found: 481.1193; $\Delta 1.0 \mathrm{ppm}$.

(R)-N-((3-(3-Fluoro-4-morpholinophenyl)-2-oxooxazolidin5-yl)methyl)-2-(trifluoromethyl)benzenesulfonamide (3j)

Off-white solid, yield: $87 \%$; mp 102.5-104.1 ${ }^{\circ} \mathrm{C}$; ${ }^{1} \mathrm{H}$ NMR (500 MHz, DMSO- $\left.d_{6}\right) \delta 8.54(\mathrm{t}, J 7.5 \mathrm{~Hz}, 1 \mathrm{H})$, $8.11(\mathrm{~d}, J 5.0 \mathrm{~Hz}, 1 \mathrm{H}), 7.98(\mathrm{dd}, J 0.8,7.7 \mathrm{~Hz}, 1 \mathrm{H}), 7.91$ $7.88(\mathrm{~m}, 1 \mathrm{H}), 7.84(\mathrm{t}, J 7.5 \mathrm{~Hz}, 1 \mathrm{H}), 7.47(\mathrm{dd}, J 5.0,15.0 \mathrm{~Hz}$, $1 \mathrm{H}), 7.15(\mathrm{dd}, J 5.0,7.5 \mathrm{~Hz}, 1 \mathrm{H}), 7.07(\mathrm{t}, J 10.0 \mathrm{~Hz}, 1 \mathrm{H})$, $4.76-4.71(\mathrm{~m}, 1 \mathrm{H}), 4.09(\mathrm{t}, J 10.0 \mathrm{~Hz}, 1 \mathrm{H}), 3.79-3.73(\mathrm{~m}$, $5 \mathrm{H}), 3.34-3.24(\mathrm{~m}, 2 \mathrm{H}), 2.97(\mathrm{t}, J 5.0 \mathrm{~Hz}, 4 \mathrm{H}) ;{ }^{13} \mathrm{C} \mathrm{NMR}$ $\left(125 \mathrm{MHz}, \mathrm{DMSO}-d_{6}\right) \delta 154.6(\mathrm{~d}, J 242.5 \mathrm{~Hz}), 153.9$, $139.5(\mathrm{~d}, J 1.3 \mathrm{~Hz}), 135.6(\mathrm{~d}, J 8.8 \mathrm{~Hz}), 133.4,133.36$ $(\mathrm{d}, J 11.3 \mathrm{~Hz}), 133.0,129.8,128.5$ (q, $J 6.3 \mathrm{~Hz}), 126.1$ (q, $J 32.5 \mathrm{~Hz}), 122.9$ (q, $J 272.5 \mathrm{~Hz}), 119.3(\mathrm{~d}, J 3.8 \mathrm{~Hz})$, 114.1 (d, $J 3.8 \mathrm{~Hz}), 106.6$ (d, $J 26.3 \mathrm{~Hz}), 71.2,66.2,50.7$ (d, $J 2.5 \mathrm{~Hz}$ ), 46.9, 45.5; HRMS (ESI) $\mathrm{m} / z$, calculated for $\mathrm{C}_{21} \mathrm{H}_{22} \mathrm{~F}_{4} \mathrm{~N}_{3} \mathrm{O}_{5} \mathrm{~S}[\mathrm{M}+\mathrm{H}]^{+}:$504.1211, found: 504.1214; $\Delta 0.6 \mathrm{ppm}$.

(R)-N-((3-(3-Fluoro-4-morpholinophenyl)-2-oxooxazolidin5-yl)methyl)quinoline-8-sulfonamide (3k)

White solid, yield: $96 \%$; mp 100.2-100.8 ${ }^{\circ} \mathrm{C}$; ${ }^{1} \mathrm{H}$ NMR $\left(500 \mathrm{MHz}, \mathrm{DMSO}-d_{6}\right) \delta 9.04-9.03(\mathrm{~m}, 1 \mathrm{H}), 8.52-8.50$ (m, 1H), 8.34-8.27 (m, 2H), 7.77-7.65 (m, 3H), 7.35-7.32 (m, 1H), 7.04-7.00 (m, 2H), 4.71-4.66 (m, 1H), $3.98(\mathrm{t}$, $J 7.5 \mathrm{~Hz}, 1 \mathrm{H}), 3.76-3.73(\mathrm{~m}, 5 \mathrm{H}), 3.34-3.25(\mathrm{~m}, 2 \mathrm{H}), 2.96$ (t, $J 5.0 \mathrm{~Hz}, 4 \mathrm{H}) ;{ }^{13} \mathrm{C}$ NMR $\left(125 \mathrm{MHz}\right.$, DMSO- $\left.d_{6}\right) \delta 154.5$ (d, $J 241.3 \mathrm{~Hz}), 153.7,151.3,142.6,137.0,136.6,135.5$ (d, $J 8.8 \mathrm{~Hz}), 133.7,133.3(\mathrm{~d}, J 10.0 \mathrm{~Hz}), 130.5,128.6$, 125.7, 122.5, 119.2 (d, J 5.0 Hz), 113.9 (d, J3.8 Hz), 106.5 (d, $J$ 25.0 Hz), 71.3, 66.2, 50.7 (d, $J$ 2.5 Hz), 46.8, 45.5; HRMS (ESI) $m / z$, calculated for $\mathrm{C}_{23} \mathrm{H}_{24} \mathrm{FN}_{4} \mathrm{O}_{5} \mathrm{~S}[\mathrm{M}+\mathrm{H}]^{+}$: 487.1446, found: $487.1451 ; \Delta 1.0 \mathrm{ppm}$.

(R)-N-((2-Oxo-3-(4-(3-oxomorpholino)phenyl)oxazolidin5-yl)methyl)benzenesulfonamide (3I)

White solid, yield: 90\%; mp 158.5-159.3 ${ }^{\circ} \mathrm{C} ;{ }^{1} \mathrm{H}$ NMR $\left(500 \mathrm{MHz}, \mathrm{DMSO}-d_{6}\right) \delta 8.16(\mathrm{t}, J 7.5 \mathrm{~Hz}, 1 \mathrm{H}), 7.83(\mathrm{~d}$, $J 10.0 \mathrm{~Hz}, 2 \mathrm{H}), 7.68-7.54(\mathrm{~m}, 5 \mathrm{H}), 7.43-7.40(\mathrm{~m}, 2 \mathrm{H})$, $4.75-4.70(\mathrm{~m}, 1 \mathrm{H}), 4.20(\mathrm{~s}, 2 \mathrm{H}), 4.12(\mathrm{t}, J 7.5 \mathrm{~Hz}, 1 \mathrm{H})$, 3.98-3.96 (m, 2H), 3.83-3.79 (m, 1H), $3.72(\mathrm{t}, J 5.0 \mathrm{~Hz}$, $2 \mathrm{H}), 3.18-3.08(\mathrm{~m}, 2 \mathrm{H}) ;{ }^{13} \mathrm{C}$ NMR (125 MHz, DMSO- $d_{6}$ ) $\delta 166.0,154.0,140.4,137.1,136.5,132.6,129.3,126.5$,
126.0, 118.3, 71.2, 67.8, 63.5, 49.1, 46.9, 45.2; HRMS (ESI) $m / z$, calculated for $\mathrm{C}_{20} \mathrm{H}_{22} \mathrm{~N}_{3} \mathrm{O}_{6} \mathrm{~S}[\mathrm{M}+\mathrm{H}]^{+}: 432.1224$, found: $432.1231 ; \Delta 1.6 \mathrm{ppm}$.

(R)-4-Methyl-N-((2-oxo-3-(4-(3-oxomorpholino)phenyl) oxazolidin-5-yl)methyl)benzenesulfonamide (3m)

White solid, yield: 87\%; mp 173.1-174.2 ${ }^{\circ} \mathrm{C}$; ${ }^{1} \mathrm{H}$ NMR $\left(500 \mathrm{MHz}\right.$, DMSO- $\left.d_{6}\right) \delta 8.06(\mathrm{t}, J 7.5 \mathrm{~Hz}, 1 \mathrm{H}), 7.71(\mathrm{~d}$, $J 5.0 \mathrm{~Hz}, 2 \mathrm{H}), 7.56-7.53(\mathrm{~m}, 2 \mathrm{H}), 7.43-7.39(\mathrm{~m}, 4 \mathrm{H}), 4.74-$ $4.69(\mathrm{~m}, 1 \mathrm{H}), 4.20(\mathrm{~s}, 2 \mathrm{H}), 4.11(\mathrm{t}, J 10.0 \mathrm{~Hz}, 1 \mathrm{H}), 3.98-3.96$ $(\mathrm{m}, 2 \mathrm{H}), 3.81-3.78(\mathrm{~m}, 1 \mathrm{H}), 3.72(\mathrm{t}, J 5.0 \mathrm{~Hz}, 2 \mathrm{H}), 3.15-3.04$ $(\mathrm{m}, 2 \mathrm{H}), 2.38$ (s, 3H); ${ }^{13} \mathrm{C}$ NMR (125 MHz, DMSO- $\left.d_{6}\right) \delta$ 166.0, 154.0, 142.9, 137.5, 137.1, 136.5, 129.7, 126.5, 126.0, 118.3, 71.2, 67.8, 63.5, 49.1, 46.9, 45.2, 21.0; HRMS (ESI) $\mathrm{m} / z$, calculated for $\mathrm{C}_{21} \mathrm{H}_{24} \mathrm{~N}_{3} \mathrm{O}_{6} \mathrm{~S}[\mathrm{M}+\mathrm{H}]^{+}$: 446.1380, found: $446.1385 ; \Delta 1.1 \mathrm{ppm}$.

(R)-4-Methoxy- $N$-((2-oxo-3-(4-(3-oxomorpholino)phenyl) oxazolidin-5-yl)methyl)benzenesulfonamide (3n)

Off-yellow solid, yield: $90 \%$; mp 142.2-143.4 ${ }^{\circ} \mathrm{C}$; ${ }^{1} \mathrm{H}$ NMR (500 MHz, DMSO- $\left.d_{6}\right) \delta 7.98(\mathrm{t}, J 5.0 \mathrm{~Hz}, 1 \mathrm{H})$, 7.77-7.74 (m, 2H), 7.57-7.54 (m, 2H), 7.43-7.40 (m, 2H), 7.14-7.11 (m, 2H), 4.74-4.70 (m, 1H), $4.20(\mathrm{~s}, 2 \mathrm{H}), 4.12$ (t, $J 10.0 \mathrm{~Hz}, 1 \mathrm{H}), 3.98-3.96(\mathrm{~m}, 2 \mathrm{H}), 3.84(\mathrm{~s}, 3 \mathrm{H}), 3.82-$ $3.79(\mathrm{~m}, 1 \mathrm{H}), 3.72(\mathrm{t}, J 5.0 \mathrm{~Hz}, 2 \mathrm{H}), 3.14-3.03(\mathrm{~m}, 2 \mathrm{H})$; ${ }^{13} \mathrm{C}$ NMR (125 MHz, DMSO- $\left.d_{6}\right) \delta 166.0,162.3,154.0$, 137.1, 136.5, 132.0, 128.7, 126.0, 118.3, 114.4, 71.2, 67.8, 63.5, 55.7, 49.0, 46.9, 45.2; HRMS (ESI) $\mathrm{m} / \mathrm{z}$, calculated for $\mathrm{C}_{21} \mathrm{H}_{24} \mathrm{~N}_{3} \mathrm{O}_{7} \mathrm{~S}[\mathrm{M}+\mathrm{H}]^{+}$: 462.1329, found: 462.1336; $\Delta 1.5 \mathrm{ppm}$.

(R)-4-Fluoro- $N$-((2-oxo-3-(4-(3-oxomorpholino)phenyl) oxazolidin-5-yl)methyl)benzenesulfonamide (30)

White solid, yield: $86 \%$; mp 176.2-177.6 ${ }^{\circ} \mathrm{C}$; ${ }^{1} \mathrm{H}$ NMR $\left(500 \mathrm{MHz}, \mathrm{DMSO}-d_{6}\right) \delta 8.20(\mathrm{t}, J 7.5 \mathrm{~Hz}, 1 \mathrm{H}), 7.89(\mathrm{t}$, $J 5.0 \mathrm{~Hz}, 2 \mathrm{H}), 7.57-7.54(\mathrm{~m}, 2 \mathrm{H}), 7.47-7.40(\mathrm{~m}, 4 \mathrm{H})$, $4.75-4.70(\mathrm{~m}, 1 \mathrm{H}), 4.20(\mathrm{~s}, 2 \mathrm{H}), 4.13(\mathrm{t}, J 10.0 \mathrm{~Hz}, 1 \mathrm{H})$, 3.98-3.96 (m, 2H), 3.82-3.80 (m, 1H), $3.72(\mathrm{t}, J 5.0 \mathrm{~Hz}$, 2H), 3.20-3.09 (m, 2H); ${ }^{13} \mathrm{C}$ NMR (125 MHz, DMSO- $d_{6}$ ) $\delta$ 166.0, $164.2(\mathrm{~d}, J 248.8 \mathrm{~Hz}), 154.0,137.1,136.8(\mathrm{~d}$, $J 3.8 \mathrm{~Hz}), 136.5,129.5(\mathrm{~d}, J 10.0 \mathrm{~Hz}), 126.0,118.3,116.5$ (d, $J 22.5 \mathrm{~Hz}$ ), 71.2, 67.8, 63.5, 49.1, 46.9, 45.2; HRMS (ESI) $m / z$, calculated for $\mathrm{C}_{20} \mathrm{H}_{21} \mathrm{FN}_{3} \mathrm{O}_{6} \mathrm{~S}[\mathrm{M}+\mathrm{H}]^{+}: 450.1130$, found: $450.1135 ; \Delta 1.1 \mathrm{ppm}$.

(R)-4-Chloro- $N$-((2-oxo-3-(4-(3-oxomorpholino)phenyl) oxazolidin-5-yl)methyl)benzenesulfonamide (3p)

White solid, yield: $91 \%$; $\mathrm{mp}$ 187.4-188.9 ${ }^{\circ} \mathrm{C}$; ${ }^{1} \mathrm{H}$ NMR $\left(500 \mathrm{MHz}, \mathrm{DMSO}-d_{6}\right) \delta 8.19(\mathrm{t}, J 7.5 \mathrm{~Hz}, 1 \mathrm{H}), 7.77-7.74$ $(\mathrm{m}, 2 \mathrm{H}), 7.62-7.60(\mathrm{~m}, 2 \mathrm{H}), 7.49-7.46(\mathrm{~m}, 2 \mathrm{H}), 7.35-7.33$ (m, 2H), 4.68-4.63 (m, 1H), $4.12(\mathrm{~s}, 2 \mathrm{H}), 4.05(\mathrm{t}, J 7.5 \mathrm{~Hz}$, 
1H), $3.90(\mathrm{t}, J 5.0 \mathrm{~Hz}, 2 \mathrm{H}), 3.72(\mathrm{dd}, J 5.0,10.0 \mathrm{~Hz}$, $1 \mathrm{H}), 3.64(\mathrm{t}, J 5.0 \mathrm{~Hz}, 2 \mathrm{H}), 3.13-3.02(\mathrm{~m}, 2 \mathrm{H}) ;{ }^{13} \mathrm{C} \mathrm{NMR}$ $\left(125 \mathrm{MHz}, \mathrm{DMSO}-d_{6}\right) \delta 166.0,154.0,139.3,137.5,137.1$, 136.5, 129.5, 128.5, 126.0, 118.3, 71.2, 67.8, 63.5, 49.1, 46.9, 45.2; HRMS (ESI) $m / z$, calculated for $\mathrm{C}_{20} \mathrm{H}_{21} \mathrm{C}_{1} \mathrm{~N}_{3} \mathrm{O}_{6} \mathrm{~S}$ $[\mathrm{M}+\mathrm{H}]^{+}:$466.0834, found: 466.0839; $\Delta 1.1 \mathrm{ppm}$.

(R)-N-((2-Oxo-3-(4-(3-oxomorpholino)phenyl)oxazolidin5-yl)methyl)-4-(trifluoromethyl)benzenesulfonamide (3q)

White solid, yield: 73\%; mp 171.3-172.1 ${ }^{\circ} \mathrm{C} ;{ }^{1} \mathrm{H}$ NMR $\left(500 \mathrm{MHz}, \mathrm{DMSO}-d_{6}\right) \delta 8.43(\mathrm{t}, J 10.0 \mathrm{~Hz}, 1 \mathrm{H}), 8.02(\mathrm{q}$, $J 10.0 \mathrm{~Hz}, 4 \mathrm{H}), 7.55(\mathrm{~d}, J 10.0 \mathrm{~Hz}, 2 \mathrm{H}), 7.42(\mathrm{~d}, J 5.0 \mathrm{~Hz}$, $2 \mathrm{H}), 4.76-4.71(\mathrm{~m}, 1 \mathrm{H}), 4.20(\mathrm{~s}, 2 \mathrm{H}), 4.13(\mathrm{t}, J 7.5 \mathrm{~Hz}, 1 \mathrm{H})$, $3.98(\mathrm{t}, J 5.0 \mathrm{~Hz}, 2 \mathrm{H}), 3.81-3.78(\mathrm{~m}, 1 \mathrm{H}), 3.72(\mathrm{t}, J 5.0 \mathrm{~Hz}$, $2 \mathrm{H}), 3.26-3.14(\mathrm{~m}, 2 \mathrm{H}) ;{ }^{13} \mathrm{C}$ NMR (125 MHz, DMSO- $\left.d_{6}\right)$ $\delta$ 166.0, 153.9, 144.4, 137.1, 136.5, $132.3(\mathrm{q}, J 32.1 \mathrm{~Hz})$, 127.5, 126.6 (q, $J 3.8 \mathrm{~Hz}), 126.0,123.5$ (q, $J 271.3 \mathrm{~Hz})$, 118.3, 71.2, 67.8, 63.5, 49.1, 46.8, 45.2; HRMS (ESI) $\mathrm{m} / \mathrm{z}$, calculated for $\mathrm{C}_{21} \mathrm{H}_{21} \mathrm{~F}_{3} \mathrm{~N}_{3} \mathrm{O}_{6} \mathrm{~S}[\mathrm{M}+\mathrm{H}]^{+}: 500.1098$, found: 500.1103; $\Delta 1.0 \mathrm{ppm}$.

(R)-3-Fluoro- $N$-((2-oxo-3-(4-(3-oxomorpholino)phenyl) oxazolidin-5-yl)methyl)benzenesulfonamide (3r)

White solid, yield: 83\%; mp 172.9-173.6 ${ }^{\circ} \mathrm{C}$; ${ }^{1} \mathrm{H}$ NMR $\left(500 \mathrm{MHz}, \mathrm{DMSO}-d_{6}\right) \delta 8.29(\mathrm{t}, J 5.0 \mathrm{~Hz}, 1 \mathrm{H}), 7.70-$ $7.61(\mathrm{~m}, 3 \mathrm{H}), 7.56-7.50(\mathrm{~m}, 3 \mathrm{H}), 7.43-7.40(\mathrm{~m}, 2 \mathrm{H})$, 4.75-4.71 (m, 1H), $4.20(\mathrm{~s}, 2 \mathrm{H}), 4.13(\mathrm{t}, J 10.0 \mathrm{~Hz}, 1 \mathrm{H})$, 3.98-3.96 (m, 2H), $3.80(\mathrm{dd}, J 5.0,10.0 \mathrm{~Hz}, 1 \mathrm{H}), 3.72(\mathrm{t}$, $J$ 5.0 Hz, 2H), 3.24-3.12 (m, 2H); ${ }^{13} \mathrm{C}$ NMR $(125 \mathrm{MHz}$, DMSO- $\left.d_{6}\right) \delta 166.0,161.8(\mathrm{~d}, J 246.3 \mathrm{~Hz}), 154.0,142.5$ $(\mathrm{d}, J 6.3 \mathrm{~Hz}), 137.1,136.5,131.7(\mathrm{~d}, J 7.5 \mathrm{~Hz}), 126.0$, 122.7 (d, $J 10.0 \mathrm{~Hz}), 119.8$ (d, $J 20.0 \mathrm{~Hz}), 118.3,113.6$ (d, $J 23.8 \mathrm{~Hz}$ ), 71.2, 67.8, 63.5, 49.1, 46.9, 45.2; HRMS (ESI) $\mathrm{m} / z$, calculated for $\mathrm{C}_{20} \mathrm{H}_{21} \mathrm{FN}_{3} \mathrm{O}_{6} \mathrm{~S}[\mathrm{M}+\mathrm{H}]^{+}$: 450.1130, found: $450.1134 ; \Delta 0.9 \mathrm{ppm}$.

(R)-N-((2-Oxo-3-(4-(3-oxomorpholino)phenyl)oxazolidin5-yl)methyl)-3-(trifluoromethyl)benzenesulfonamide (3s)

Off-yellow solid, yield: $80 \%$; mp $158.4-159.5{ }^{\circ} \mathrm{C}$; ${ }^{1} \mathrm{H}$ NMR $\left(500 \mathrm{MHz}\right.$, DMSO- $\left.d_{6}\right) \delta 8.40(\mathrm{t}, J 5.0 \mathrm{~Hz}, 1 \mathrm{H})$, $8.14(\mathrm{~d}, J 5.0 \mathrm{~Hz}, 2 \mathrm{H}), 8.06(\mathrm{~d}, J 5.0 \mathrm{~Hz}, 1 \mathrm{H}), 7.87(\mathrm{t}$, $J 7.5 \mathrm{~Hz}, 1 \mathrm{H}), 7.56-7.53(\mathrm{~m}, 2 \mathrm{H}), 7.43-7.40(\mathrm{~m}, 2 \mathrm{H}), 4.76-$ $4.72(\mathrm{~m}, 1 \mathrm{H}), 4.20(\mathrm{~s}, 2 \mathrm{H}), 4.14(\mathrm{t}, J 10.0 \mathrm{~Hz}, 1 \mathrm{H}), 3.99-3.97$ $(\mathrm{m}, 2 \mathrm{H}), 3.80(\mathrm{dd}, J 5.0,10.0 \mathrm{~Hz}, 1 \mathrm{H}), 3.72(\mathrm{t}, J 5.0 \mathrm{~Hz}$, $2 \mathrm{H}), 3.26-3.15(\mathrm{~m}, 2 \mathrm{H}) ;{ }^{13} \mathrm{C}$ NMR (125 MHz, DMSO- $\left.d_{6}\right)$ $\delta$ 166.0, 154.0, 141.7, 137.1, 136.5, 131.0, 130.6, 130.0 (q, $J 32.5 \mathrm{~Hz}), 129.4$ (q, J3.8 Hz), 126.0, $123.5(\mathrm{q}, J 271.3 \mathrm{~Hz})$, 123.1 (q, J3.8 Hz), 118.3, 71.2, 67.8, 63.5, 49.1, 46.9, 45.2; HRMS (ESI) $m / z$, calculated for $\mathrm{C}_{21} \mathrm{H}_{21} \mathrm{~F}_{3} \mathrm{~N}_{3} \mathrm{O}_{6} \mathrm{~S}[\mathrm{M}+\mathrm{H}]^{+}$: 500.1098, found: $500.1103 ; \Delta 1.0 \mathrm{ppm}$.
(R)-3-Nitro- $N$-((2-oxo-3-(4-(3-oxomorpholino)phenyl) oxazolidin-5-yl)methyl)benzenesulfonamide (3t)

Off-yellow solid, yield: $82 \%$; mp 137.7-138.8 ${ }^{\circ} \mathrm{C}$; ${ }^{1} \mathrm{H}$ NMR (500 MHz, DMSO- $\left.d_{6}\right) \delta 8.49(\mathrm{t}, J 1.9 \mathrm{~Hz}, 1 \mathrm{H})$, $8.45(\mathrm{t}, J 5.0 \mathrm{~Hz}, 1 \mathrm{H}), 8.41-8.39(\mathrm{~m}, 1 \mathrm{H}), 8.17-8.15(\mathrm{~m}$, $1 \mathrm{H}), 7.83(\mathrm{t}, J 7.5 \mathrm{~Hz}, 1 \mathrm{H}), 7.47-7.44(\mathrm{~m}, 2 \mathrm{H}), 7.35-7.32$ $(\mathrm{m}, 2 \mathrm{H}), 4.68-4.63(\mathrm{~m}, 1 \mathrm{H}), 4.13(\mathrm{~s}, 2 \mathrm{H}), 4.05(\mathrm{t}, J 7.5 \mathrm{~Hz}$, $1 \mathrm{H}), 3.90(\mathrm{t}, J 5.0 \mathrm{~Hz}, 2 \mathrm{H}), 3.70(\mathrm{dd}, J 5.0,10.0 \mathrm{~Hz}$, $1 \mathrm{H}), 3.65(\mathrm{t}, J 5.0 \mathrm{~Hz}, 2 \mathrm{H}), 3.22-3.10(\mathrm{~m}, 2 \mathrm{H}) ;{ }^{13} \mathrm{C} \mathrm{NMR}$ $\left(125 \mathrm{MHz}\right.$, DMSO- $\left.d_{6}\right) \delta 166.0,153.9,148.0,142.1,137.1$, 136.4, 132.5, 131.4, 127.2, 126.0, 121.4, 118.2, 71.1, 67.8, 63.5, 49.1, 46.8, 45.2; HRMS (ESI) $\mathrm{m} / z$, calculated for $\mathrm{C}_{20} \mathrm{H}_{21} \mathrm{~N}_{4} \mathrm{O}_{8} \mathrm{~S}[\mathrm{M}+\mathrm{H}]^{+}: 477.1075$, found: 477.1080; $\Delta 1.0 \mathrm{ppm}$.

(R)-N-((2-Oxo-3-(4-(3-oxomorpholino)phenyl)oxazolidin5-yl)methyl)-2-(trifluoromethyl)benzenesulfonamide (3u)

White solid, yield: $93 \%$; mp 127.6-128.9 ${ }^{\circ} \mathrm{C} ;{ }^{1} \mathrm{H}$ NMR $\left(500 \mathrm{MHz}, \mathrm{DMSO}-d_{6}\right) \delta 8.56(\mathrm{t}, J 7.5 \mathrm{~Hz}, 1 \mathrm{H}), 8.11(\mathrm{~d}$, $J 5.0 \mathrm{~Hz}, 1 \mathrm{H}), 7.98(\mathrm{dd}, J 2.5,7.5 \mathrm{~Hz}, 1 \mathrm{H}), 7.91-7.88$ $(\mathrm{m}, 1 \mathrm{H}), 7.84(\mathrm{t}, J 7.5 \mathrm{~Hz}, 1 \mathrm{H}), 7.56-7.53(\mathrm{~m}, 2 \mathrm{H})$, 7.43-7.40 (m, 2H), 4.78-4.73 (m, 1H), 4.20 (s, 2H), 4.14 (t, $J 10.0 \mathrm{~Hz}, 1 \mathrm{H}), 3.99-3.97(\mathrm{~m}, 2 \mathrm{H}), 3.83(\mathrm{dd}, J 5.0$, $10.0 \mathrm{~Hz}, 1 \mathrm{H}), 3.72(\mathrm{t}, J 5.0 \mathrm{~Hz}, 2 \mathrm{H}), 3.34-3.26(\mathrm{~m}, 2 \mathrm{H})$; ${ }^{13} \mathrm{C}$ NMR $\left(125 \mathrm{MHz}\right.$, DMSO- $\left.d_{6}\right) \delta 166.0,153.9,139.5$, 137.1, 136.5, 133.4, 133.0, 129.8, 128.5 (q, $J 6.3 \mathrm{~Hz}$ ), 126.1 (q, J 32.5 Hz), 126.0, 122.9 (q, J 272.5 Hz), 118.3, 71.2, 67.8, 63.5, 49.1, 46.9, 45.5; HRMS (ESI) $\mathrm{m} / z$, calculated for $\mathrm{C}_{21} \mathrm{H}_{21} \mathrm{~F}_{3} \mathrm{~N}_{3} \mathrm{O}_{6} \mathrm{~S}[\mathrm{M}+\mathrm{H}]^{+}: 500.1098$, found: 500.1101; $\Delta 0.6$ ppm.

(R)-N-((2-Oxo-3-(4-(3-oxomorpholino)phenyl)oxazolidin5 -yl)methyl)quinoline-8-sulfonamide (3v)

White solid, yield: 75\%; mp 222.4-224.1 ${ }^{\circ} \mathrm{C} ;{ }^{1} \mathrm{H}$ NMR $\left(500 \mathrm{MHz}, \mathrm{DMSO}-d_{6}\right) \delta 8.96(\mathrm{dd}, J 1.7,4.2 \mathrm{~Hz}, 1 \mathrm{H})$, $8.43(\mathrm{dd}, J 1.7,8.4 \mathrm{~Hz}, 1 \mathrm{H}), 8.26(\mathrm{dd}, J 1.2,7.3 \mathrm{~Hz}, 1 \mathrm{H})$, $8.20(\mathrm{dd}, J 1.2,8.3 \mathrm{~Hz}, 1 \mathrm{H}), 7.69-7.64(\mathrm{~m}, 2 \mathrm{H}), 7.59(\mathrm{q}$, $J$ 4.2 Hz, 1H), 7.36-7.28 (m, 4H), 4.65-4.60 (m, 1H), 4.13 (s, 2H), $3.95(\mathrm{t}, J 10.0 \mathrm{~Hz}, 1 \mathrm{H}), 3.91-3.89(\mathrm{~m}, 2 \mathrm{H}), 3.72$ (dd, J 5.0, $10.0 \mathrm{~Hz}, 1 \mathrm{H}), 3.64(\mathrm{t}, J 5.0 \mathrm{~Hz}, 2 \mathrm{H}), 3.26-3.18$ (m, $2 \mathrm{H}) ;{ }^{13} \mathrm{C}$ NMR $\left(125 \mathrm{MHz}\right.$, DMSO- $\left.d_{6}\right) \delta 166.0,153.8$, 151.3, 142.6, 137.1, 137.0, 136.6, 136.4, 133.7, 130.5, 128.6, 125.9, 125.7, 122.5, 118.1, 71.3, 67.8, 63.5, 49.1, 46.8, 45.5; HRMS (ESI) $\mathrm{m} / z$, calculated for $\mathrm{C}_{23} \mathrm{H}_{23} \mathrm{~N}_{4} \mathrm{O}_{6} \mathrm{~S}$ $[\mathrm{M}+\mathrm{H}]^{+}:$483.1333, found: 483.1337; $\Delta 0.8 \mathrm{ppm}$.

\section{Biological assays}

\section{Materials}

The fluorescent intensity was monitored by envision multi-mode reader (PerkinElmer, Llantrisant, United 
Kingdom). SARS-COV-2 3CL pro inhibitor screening kit was purchased from Xiamen Lablead Biotechnology Co., Ltd. (Xiamen, China). All chemicals were analytically pure and purchased from commercial sources (Shanghai Baishun Biotechnology Co., Ltd., Shanghai, China).

\section{$3 C L^{\text {pro }}$ inhibition rates}

The $3 \mathrm{CL}^{\text {pro }}$ enzyme assay was conducted in 384-well black microplates (PerkinElmer, Boston, USA) with a total volume of $41 \mu \mathrm{L}$. In a 384-well plate format, $20 \mu \mathrm{L}$ enzyme in reaction buffer was added into each well, followed by the addition of $1 \mu \mathrm{L}$ target compound (different concentrations dissolved in DMSO). SARS-COV-2 $3 \mathrm{CL}^{\mathrm{pro}}$ and compound were mixed and pre-incubated at $30{ }^{\circ} \mathrm{C}$ for $10 \mathrm{~min}$. Fluorescent intensity was measured at different time points on a plate reader with $\lambda_{\mathrm{Ex}}=320 \mathrm{~nm}$ and $\lambda_{\mathrm{Em}}=405 \mathrm{~nm}$ after the addition of $20 \mu \mathrm{L}$ substrate with the cleavage site of $\mathrm{M}^{\text {pro }}$ (indicated by the arrow, MCA-AVLQ $\downarrow$ SGFR-K(Dnp)K). The experiment was conducted at room temperature (RT).

First, $0.2 \mu \mathrm{M}$ (final concentration) SARS-CoV-2 3CL pro and different concentrations of substrates $(2.5-100 \mu \mathrm{M})$ were mixed and then the analysis was started. The fluorescent intensity was monitored by envision multi-mode reader. The kinetic parameters Michaelis constant $\left(\mathrm{K}_{\mathrm{m}}\right)$ and catalytic constant $\left(\mathrm{K}_{\text {cat }}\right)$ were calculated by a double reciprocal diagram. Then all compounds with a concentration of $50 \mu \mathrm{M}$ were screened. When different compounds were added to the mixture, the change of initial rate was calculated to evaluate the inhibitory effect of the compounds. The specific methods are as follows: (i) $20 \mu \mathrm{L}$ enzyme was incubated with $1 \mu \mathrm{L}$ compound $(2 \mathrm{mM})$ at $30{ }^{\circ} \mathrm{C}$ for $10 \mathrm{~min}$, and the substrate was added rapidly, the final concentration of substrate was $20 \mu \mathrm{M}$; (ii) the absorbance was measured by excitation at $320 \mathrm{~nm}$ and emission at $405 \mathrm{~nm}$ for $10 \mathrm{~min}$; (iii) plot of the growth value of time and excitation light relative to 0 time, slope calculation, and comparison with the slope without compound, which is the inhibition rate of a drug on enzyme activity.

Half maximal inhibitory concentration $\left(\mathrm{IC}_{50}\right)$ of $3 \mathrm{CL}^{\text {pro }}$ inhibition

For the determination of the $\mathrm{IC}_{50}, 0.1 \mathrm{mM}$ SARS-CoV-2 $3 \mathrm{CL}^{\text {pro }}$ was incubated with compounds at various concentrations $(0.048-50 \mu \mathrm{M})$ in an assay buffer at $30^{\circ} \mathrm{C}$ for $10 \mathrm{~min}$. Afterward, the reaction was initiated by adding the substrate at a $20 \mu \mathrm{M}$ final concentration (final well volume: $41 \mu \mathrm{L}$ ). The $\mathrm{IC}_{50}$ value for $\mathbf{3 g}$ was determined using the GraphPad Prism software. ${ }^{29}$

\section{Docking analysis}

Schrödinger software (version 2017-1, Maestro 9.3) ${ }^{30}$ was employed in our molecular docking study. The crystal structure of the SARS-COV-2 3CL pro complex (PDB ID: 6LU7) was retrieved from the Protein Data Bank. ${ }^{31}$ The protein $3 \mathrm{CL}^{\text {pro }}$ was prepared with the Protein Preparation Wizard panel. ${ }^{32}$ The glide grid center was set according to the geometrical center of native ligand $\mathrm{N} 3$ and the grid size was $10 \times 10 \times 10 \AA^{3}$. The native ligand and the active compound $3 \mathrm{~g}$ were prepared using the LigPrep suite. ${ }^{30}$ Then, they were docked into the active site of $3 \mathrm{CL}^{\text {pro }}$ using the induced-fit docking protocol in Schrodinger Maestro 9.3. ${ }^{30}$ All of docking results were processed by Maestro $9.3^{30}$ or PyMOL software. ${ }^{33}$ For the native ligand N3, the rootmean-square deviation (RMSD) value of the docked pose referred to crystal pose was $1.9374 \AA$, which implicated this dock process was enough reliable.

\section{Results and Discussion}

\section{Chemistry}

Target compounds $\mathbf{3 a - 3 v}$ were prepared by condensation of sulfonyl chlorides with linezolid/rivaroxaban amines (Scheme 1). Although some of the starting materials are dissolved in DMSO rather than methylene chloride, the yield in DMSO is much lower than in methylene chloride, not more than $40 \%$ in general, therefore the condensation was carried out in methylene chloride. The structures of target compounds $\mathbf{3 a}-\mathbf{3} \mathbf{v}$ were characterized by ${ }^{1} \mathrm{H}$ NMR, ${ }^{13} \mathrm{C}$ NMR, and HRMS. When linezolid amine was used as the starting material $\left(\mathrm{R}_{2}=\mathrm{F}\right)$, the carbon atom of $3-\mathrm{CH}_{2}$ of morpholine ring appears as a doublet at around $50.7 \mathrm{ppm}$ $(J 2.5 \mathrm{~Hz})$, this signal splitting is due to the through-space coupling with the space adjacent fluorine atom. ${ }^{34}$

\section{$3 C L^{\text {pro inhibitory activities }}$}

In this study, it was evaluated the inhibition activities of synthesized compounds against SARS-CoV-2 $3 \mathrm{CL}^{\text {pro }}$ using a procedure mentioned earlier. ${ }^{29}$ The inhibition rates

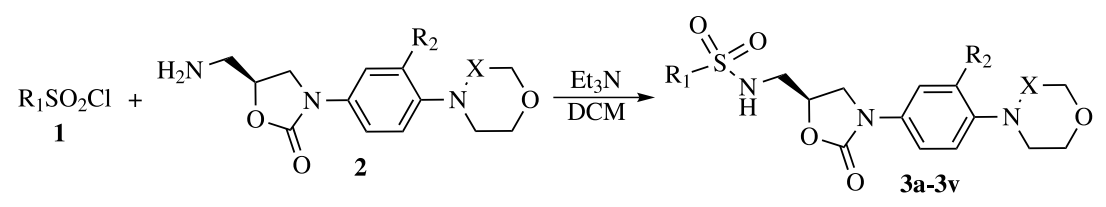

Scheme 1. Synthesis of target compounds 3a-3v. 
of target compounds $\mathbf{3 a - 3 v}$ at $50 \mu \mathrm{M}$ against SARS-CoV-2 $3 \mathrm{CL}^{\text {pro }}$ activity are shown in Table 1 . All synthesized compounds at $50 \mu \mathrm{M}$ exhibited potent inhibition on $3 \mathrm{CL}^{\text {pro }}$ activity. Especially, compounds $\mathbf{3 d}, \mathbf{3 g}$, and $\mathbf{3 h}$ at $50 \mu \mathrm{M}$ displayed remarkable inhibitory activity of
SARS-CoV-2 3CL protease, with inhibition rates of 92.2, 99.5 , and $89.3 \%$, respectively. According to these data in Table 1, we attempted to establish the preliminary SARs of these novel oxazolidinone derivatives. In general, compounds 3a-3k with $\mathrm{R}_{2}=\mathrm{F}$ and $\mathrm{X}=\mathrm{CH}_{2}$ displayed

Table 1. Inhibition rates of target compounds $\mathbf{3 a - 3 v}$ at $50 \mu \mathrm{M}$ on $3 \mathrm{CL}^{\text {pro }}$ activity

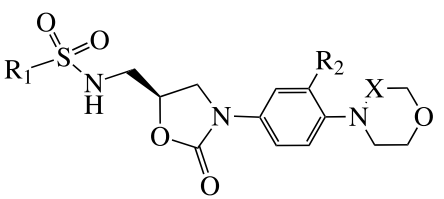

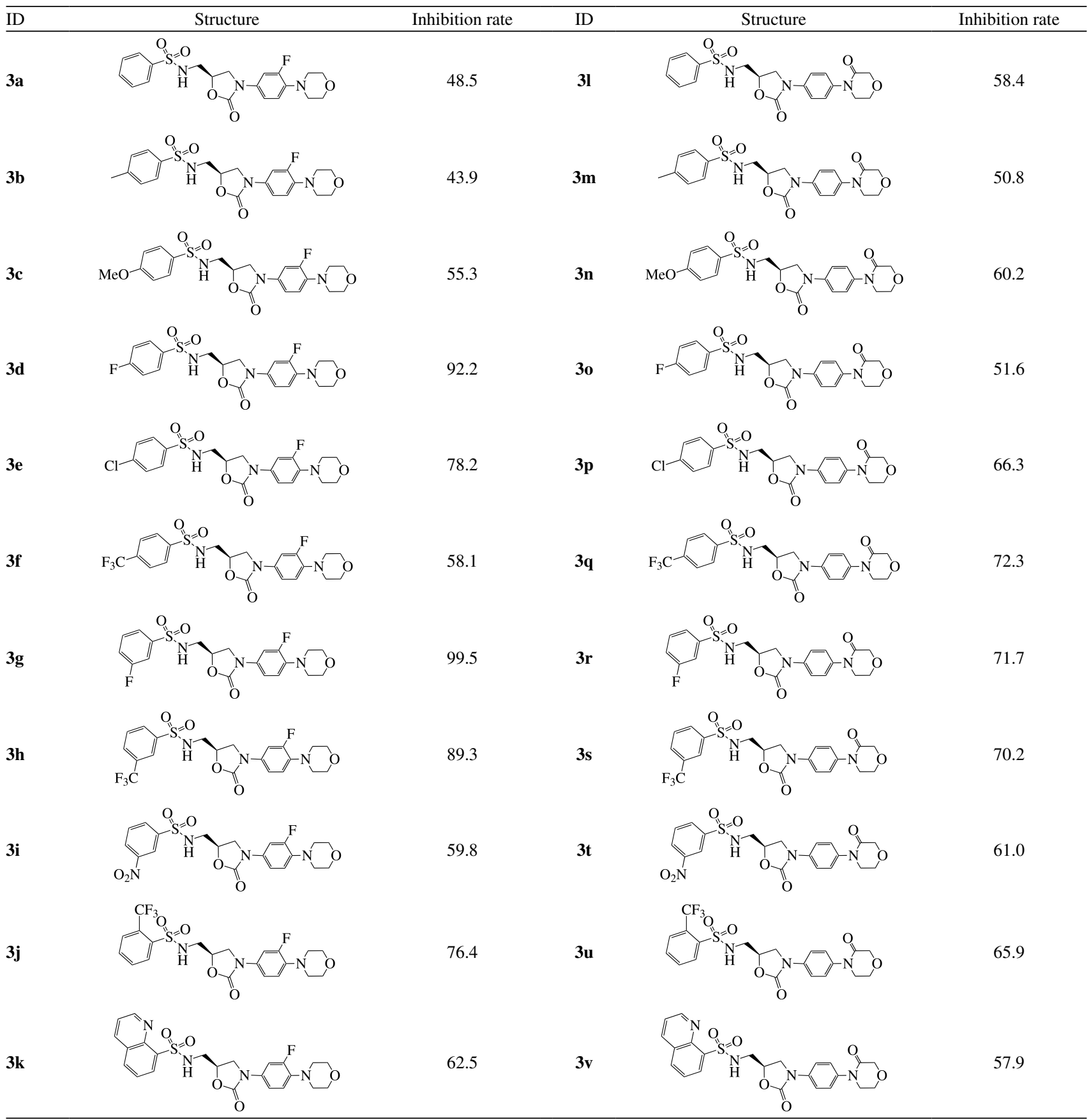


more inhibitory effect than compounds $\mathbf{3 I - 3 v}$ with $\mathrm{R}_{2}=\mathrm{H}$ and $\mathrm{X}=\mathrm{CO}$. In the target compounds $\mathbf{3 a - 3 j}$ which contain mono-substituted phenyl ring $\left(\mathrm{R}_{1}\right)$, the type and substituted position of substitutes displayed an important relationship with the inhibitory activity. When the moiety $\mathrm{R}_{1}$ was the para-mono-substituted phenyl, the introduction of a halogen atom caused a great increase in $3 \mathrm{CL}^{\text {pro }}$ inhibition. For example, both $\mathbf{3 d}\left(\mathrm{R}_{1}=4\right.$-fluorophenyl) and $3 \mathbf{e}\left(\mathrm{R}_{1}=4\right.$-chlorine phenyl) showed better inhibitory activity than $\mathbf{3 a}\left(\mathrm{R}_{1}=\right.$ phenyl), while compounds $\mathbf{3 b}$ $\left(\mathrm{R}_{1}=4\right.$-methylphenyl) and $3 \mathrm{c}\left(\mathrm{R}_{1}=4\right.$-methoxyphenyl $)$ exhibited a similar inhibition activity with $\mathbf{3 a}\left(\mathrm{R}_{1}=\right.$ phenyl), suggesting that electron donating groups substituted at phenyl ring could not improve the $3 \mathrm{CL}^{\text {pro }}$ inhibition. Additionally, 3g $\left(\mathrm{R}_{1}=3\right.$-fluorophenyl) had a better inhibitor activity than $\mathbf{3 d}\left(\mathrm{R}_{1}=4\right.$-fluorophenyl), and $\mathbf{3 h}$ $\left(\mathrm{R}_{1}=3\right.$-(trifluoromethyl)phenyl) had a better inhibitor activity than $\mathbf{3 f}\left(\mathrm{R}_{1}=4\right.$-(trifluoromethyl)phenyl) and $\mathbf{3 j}$ $\left(\mathrm{R}_{1}=2\right.$-(trifluoromethyl)phenyl), which implied that meta substitution was helpful for inhibitory activity compared with the ortho- and para-substitutions. Finally, compound $\mathbf{3 k}$ which had a quinolyl group at $\mathrm{R}_{1}$ retained moderate inhibitory activity.

At the concentration of $50 \mu \mathrm{M}$, compound $3 \mathrm{~g}$ was found to be the most potent SARS-CoV-2 3CL pro inhibitor

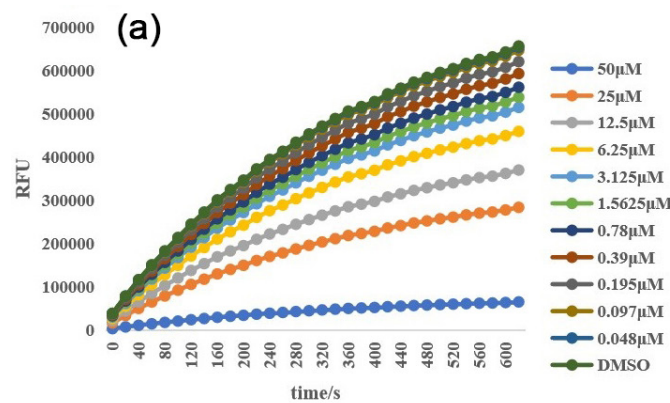

among all synthesized compounds. So, the $3 \mathrm{CL}^{\text {pro }}$ inhibitory activities of $\mathbf{3 g}$ at variable concentrations were further evaluated. As shown in Figure 2a, the inhibition of SARS-CoV-2 3CL pro by $\mathbf{3 g}$ slowly increased in the concentration range from 0 to $50 \mathrm{M}$ of compound $\mathbf{3 g}$. It suggested that $\mathbf{3 g}$ could enter into the active pocket of enzyme SARS-CoV-2 3CL ${ }^{\text {pro }}$ and inhibit its activity in a concentration dependent manner. Also, the $\mathrm{IC}_{50}$ value of compound $\mathbf{3 g}$ in inhibiting the catalytic activity of SARS-CoV-2 3CL protease was calculated by the dose-dependent inhibitory curves of $\mathbf{3 g}$. Compound $\mathbf{3 g}$ was confirmed to have a prominent inhibitory activity, with an $\mathrm{IC}_{50}$ value of $14.47 \mu \mathrm{M}$.

\section{Docking analysis of compound $\mathbf{3 g}$ with $3 \mathrm{CL}^{\text {pro }}$}

To predict the possible binding mode of compound $\mathbf{3 g}$ to the active site of SARS-CoV-2 3CL pro, docking analysis was performed using the induced-fit docking protocol in Schrodinger Maestro 9.3. ${ }^{30}$ The docking study revealed that compound $\mathbf{3 g}$ exhibited a moderate binding affinity with SARS-CoV-2 3CL pro, with a docking score of $-6.317 \mathrm{kcal} \mathrm{mol}^{-1}$ for the first top-scored docking mode shown in Figure 3. As shown in Figure 3a, compound $\mathbf{3 g}$ was well-fitted into the active pocket of

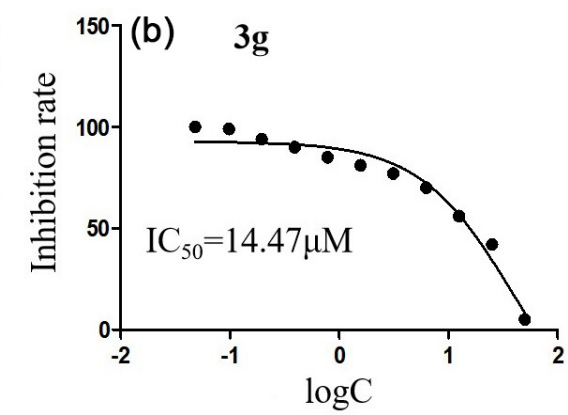

Figure 2. (a) Enzyme activities were measured using fluorogenic substrate $(20 \mu \mathrm{M})$ in the presence of compound $\mathbf{3 g}(0-50 \mu \mathrm{M})$. Over the entire $600 \mathrm{~s}$ time window, the inhibited enzyme with a different concentration of inhibitor showed a time-dependent reduction of activity; (b) inhibitory activity profiles of compound $3 \mathrm{~g}$ against SARS-CoV-2 $3 \mathrm{CL}^{\text {pro }}$.
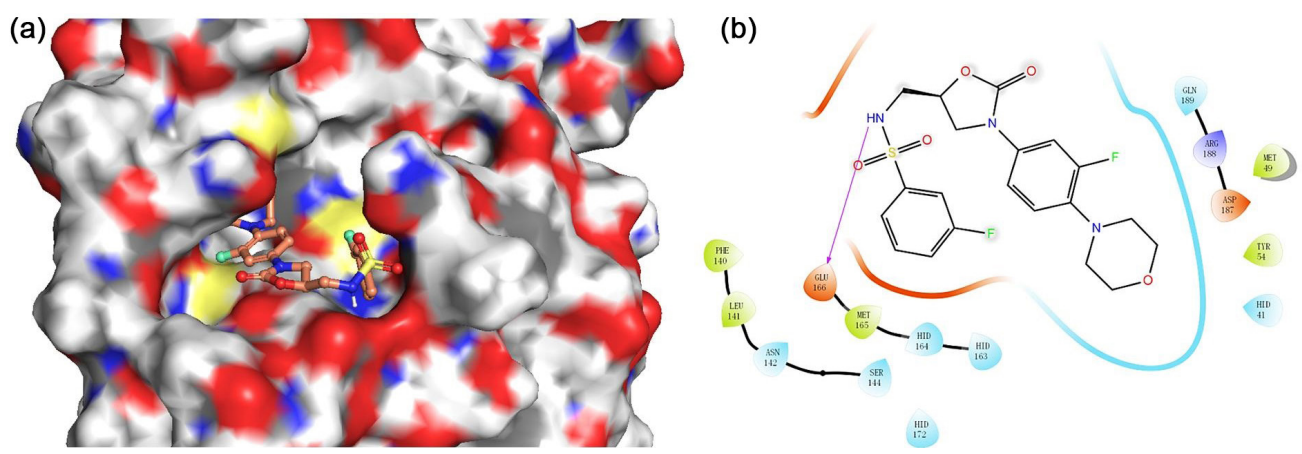

Figure 3. (a) Surface presentation of the docking mode of $3 \mathrm{CL}^{\text {pro }}$ complex with $\mathbf{3 g}$ (PDB ID: 6LU7); (b) 2D binding model of $\mathbf{3 g}$ with $3 C L^{\text {pro }}$. Hydrogen bond is indicated with purple solid arrows, color lines around $\mathbf{3 g}$ stand for the binding pocket and the residues in colors nearby established the pocket. The green denotes the hydrophobic nature of amino acids, the red denotes the acid amino acids, the purple denotes the alkalinity of amino acids, the cyan denotes the polar amino acids, and the grey points of ligand atoms denote the solvent accessibility. 
SARS-CoV-2 3CL ${ }^{\text {pro }}$. The morpholine ring of $\mathbf{3 g}$ was inside the drug binding pocket of $3 \mathrm{CL}^{\text {pro }}$. The five membered ring of $\mathbf{3 g}$ located near the solvent exposure area made close contact with SARS-CoV-2 3CL pro. Moreover, the hydrogen atom of sulfonamide of $\mathbf{3 g}$ formed a hydrogen bond (2.14 ̊̊) with Glu166 (Figure 3b). These molecular docking results further supported that $\mathbf{3 g}$ was a potential SARS-CoV-2 3CL pro inhibitor.

\section{Conclusions}

In summary, a total of 22 oxazolidinone derivatives $\mathbf{3 a - 3 v}$ were synthesized and their inhibitory activities against SARS-CoV-2 3CL ${ }^{\text {pro }}$ were screened. Compound $\mathbf{3 g}$ displayed the most potent inhibitory activity with an $\mathrm{IC}_{50}$ value of $14.47 \mu \mathrm{mol} \mathrm{L}{ }^{-1}$. Moreover, molecular docking analysis showed the modes of action of compound $3 \mathrm{~g}$ with $3 \mathrm{CL}^{\text {pro }}$, indicating that the hydrogen bond interaction plays a key role in stabilizing $\mathbf{3 g}$ in the binding pocket. Taken together, compound $\mathbf{3 g}$ may be a valuable lead compound for further development of the effective SARS-CoV-2 3CL ${ }^{\text {pro }}$ inhibitors.

\section{Supplementary Information}

Supplementary data are available free of charge at http://jbcs.sbq.org.br as PDF file.

\section{Acknowledgments}

This research was funded by the Natural Science Foundation of Ningbo (grant No. 202003N4160), Key Research Projects on Emergency Prevention and Control of New Coronavirus Infected Pneumonia from Jinhua Science and Technology Bureau (2020XG-11) and sponsored by K. C. Wong Magna Fund in Ningbo University.

\section{Author Contributions}

Shengxian Zhao was responsible for target compounds and synthetic route design, and contributions to manuscript writing; Chaojie Wang for biological assays and docking analysis; Yiming Lu, Xin Zhang, and Siyu Wu for organic synthesis work; Hui Mao for coordination of organic synthesis work and biological assays, contributions to manuscript writing.

\section{References}

1. Mahase, E.; Br. Med. J. 2020, 369, m1547.

2. Shaw, P. D.; Patel, N.; Patil, S.; Samuel, R.; Khanna, P.; Prajapati, B.; Sharun, K.; Tiwari, R.; Dhama, K.; Natesan, S.; J. Exp. Biol. Agric. Sci. 2020, 8, S103.
3. Bonilauri, P.; Rugna, G.; Life 2021, 11, 123.

4. Al-Salihi, K. A.; Khalaf, J. M.; Vet. World 2021, 14, 190.

5. Sansonetti, P. J.; EMBO Mol. Med. 2020, 12, e12463.

6. Cutler, D. M.; Summers, L. H.; J. Am. Med. Assoc. 2020, 324, 1495.

7. Corrao, G.; Rea, F.; Blangiardo, G. C.; J. Hypertens. 2021, 39, 856.

8. Kissler, S. M.; Tedijanto, C.; Goldstein, E.; Grad, Y. H.; Lipsitch, M.; Science 2020, 368, 860.

9. Jia, Z. X.; Gong, W. P.; J. Korean Med. Sci. 2021, 36, e124.

10. Triggle, C. R.; Bansal, D.; Ding, H.; Islam, M. M.; Farag, E. A. B. A.; Hadi, H. A.; Sultan, A. A.; Front. Immunol. 2021, 12, 631139.

11. Jin, Z. M.; Du, X. Y.; Xu, Y. C.; Deng, Y. Q.; Liu, M. Q.; Zhao, Y.; Zhang, B.; Li, X. F.; Zhang, L. K.; Peng, C.; Duan, Y. K.; Yu, J.; Wang, L.; Yang, K. L.; Liu, F. J.; Jiang, R. D.; Yang, X. L.; You, T.; Liu, X. C.; Yang, X. N.; Bai, F.; Liu, H.; Liu, X.; Guddat, L. W.; Xu, W. Q.; Xiao, G. F.; Qin, C. F.; Shi, Z. L.; Jiang, H. L.; Rao, Z. H.; Yang, H. T.; Nature 2020, 582, 289.

12. Dai, W. H.; Zhang, B.; Jiang, X. M.; Su, H. X.; Li, J.; Zhao, Y.; Xie, X.; Jin, Z. M.; Peng, J. J.; Liu, F. J.; Li, C. P.; Li, Y.; Bai, F.; Wang, H. F.; Cheng, X.; Cen, X. B.; Hu, S. L.; Yang, X. N.; Wang, J.; Liu, X.; Xiao, G. F.; Jiang, H. L.; Rao, Z. H.; Zhang, L. K.; Xu, Y. C.; Yang, H. T.; Liu, H.; Science 2020, 368, 1331.

13. Hoffman, R. L.; Kania, R. S.; Brothers, M. A.; Davies, J. F.; Ferre, R. A.; Gajiwala, K. S.; He, M. Y.; Hogan, R. J.; Kozminski, K.; Li, L. Y.; Lockner, J. W.; Lou, J. H.; Marra, M. T.; Mitchell Jr., L. J.; Murray, B. W.; Nieman, J. A.; Noell, S.; Planken, S. P.; Rowe, T.; Ryan, K.; Smith III, G. J.; Solowiej, J. E.; Steppan, C. M.; Taggart, B.; J. Med. Chem. 2020, 63, 12725.

14. Yang, K. S.; Ma, X. R.; Ma, Y. Y.; Alugubelli, Y. R.; Scott, D. A.; Vatansever, E. C.; Drelich, A. K.; Sankaran, B.; Geng, Z. Z.; Blankenship, L. R.; Ward, H. E.; Sheng, Y. J.; Hsu, J. C.; Kratch, K. C.; Zhao, B. Y.; Hayatshahi, H. S.; Liu, J.; Li, P. W.; Fierke, C. A.; Tseng, C. K.; Xu, S. Q.; Liu, W. R.; ChemMedChem 2021, 16, 942 .

15. Vuong, W.; Fischer, C.; Khan, M. B.; Belkum, M. J. V.; Lamer, T.; Willoughby, K. D.; Lu, J.; Arutyunova, E.; Joyce, M. A.; Saffran, H. A.; Shields, J. A.; Young, H. S.; Nieman, J. A.; Tyrrell, D. L.; Lemieux, M. J.; Vederas, J. C.; Eur. J. Med. Chem. 2021, 222, 113584.

16. Kreutzer, A. G.; Krumberger, M.; Diessner, E. M.; Parrocha, C. M. T.; Morris, M. A.; Guaglianone, G.; Butts, C. T.; Nowick, J. S.; Eur. J. Med. Chem. 2021, 221, 113530.

17. Kankanamalage, A. C. G.; Kim, Y. J.; Damalanka, V. C.; Rathnayake, A. D.; Fehr, A. R.; Mehzabeen, N.; Battaile, K. P.; Lovell, S.; Lushington, G. H.; Perlman, S.; Chang, K. O.; Groutas, W. C.; Eur. J. Med. Chem. 2018, 150, 334.

18. Zhang, L. L.; Lin, D. Z.; Kusov, Y.; Nian, Y.; Ma, Q. J.; Wang, J.; Brunn, A. V.; Leyssen, P.; Lanko, K.; Neyts, J.; Wilde, A. D.; Snijder, E. J.; Liu, H.; Hilgenfeld, R.; J. Med. Chem. 2020, 63,4562 . 
19. Sun, L. Y.; Chen, C.; Su, J. P.; Li, J. Q.; Jiang, Z. H.; Gao, H.; Chigan, J. Z.; Ding, H. H.; Zhai, L.; Yang, K. W.; Bioorg. Chem. 2021, 112, 104889.

20. Shimamoto, Y.; Hattori, Y.; Kobayashi, K.; Teruya, K.; Sanjoh, A.; Nakagawa, A.; Yamashita, E.; Akaji, K.; Bioorg. Med. Chem. 2015, 23, 876 .

21. Kumar, V.; Tan, K. P.; Wang, Y. M.; Lin, S. W.; Liang, P. H.; Bioorg. Med. Chem. 2016, 24, 3035.

22. Park, J. Y.; Kim, J. H.; Kwon, J. M.; Kwon, H. J.; Jeong, H. J.; Kim, Y. M.; Kim, D.; Lee, W. S.; Ryu, Y. B.; Bioorg. Med. Chem. 2013, 21, 3730.

23. Deshmukh, M. S.; Jain, N.; ACS Med. Chem. Lett. 2017, 8 , 1153.

24. Xue, T.; Ding, S.; Guo, B.; Zhou, Y. R.; Sun, P.; Wang, H. Y.; Chu, W. J.; Gong, G. Q.; Wang, Y. Y.; Chen, X. Y.; Yang, Y. S.; J. Med. Chem. 2014, 57, 7770.

25. Smith, C. J.; Ali, A.; Hammond, M. L.; Li, H.; Lu, Z. J.; Napolitano, J.; Taylor, G. E.; Thompson, C. F.; Anderson, M. S.; Chen, Y.; Eveland, S. S.; Guo, Q.; Hyland, S. A.; Milot, D. P.; Sparrow, C. P.; Wright, S. D.; Cumiskey, A. M.; Latham, M.; Peterson, L. B.; Rosa, R.; Pivnichny, J. V.; Tong, X. C.; Xu, S. S.; Sinclair, P. J.; J. Med. Chem. 2011, 54, 4880.

26. Ghosh, A. K.; Williams, J. N.; Ho, R. Y.; Simpson, H. M.; Hattori, S.; Hayashi, H.; Agniswamy, J.; Wang, Y. F.; Weber, I. T.; Mitsuya, H.; J. Med. Chem. 2018, 61, 9722.
27. Damalanka, V. C.; Kim, Y.; Kankanamalage, A. C. G.; Rathnayake, A. D.; Mehzabeen, N.; Battaile, K. P.; Lovell, S.; Nguyen, H. N.; Lushington, G. H.; Chang, K.; Groutas, W. C.; Eur. J. Med. Chem. 2018, 143, 881.

28. Lu, I. L.; Mahindroo, N.; Liang, P. H.; Peng, Y. H.; Kuo, C. J.; Tsai, K. C.; Hsieh, H. P.; Chao, Y. S.; Wu, S. Y.; J. Med. Chem. 2006, 49, 5154.

29. GraphPad Software; GraphPad Prism, version 8.0.0 for Windows; GraphPad Software, USA, 2019.

30. Friesner, R. A.; Murphy, R. B.; Repasky, M. P.; Schrodinger Release 2017-1: LigPrep; Schrodinger, LLC., USA, 2013.

31. PDB ID: 6LU7, the Crystal Structure of COVID-19 Main Protease in Complex with an Inhibitor N3, available at https:// www.rcsb.org/structure/6LU7, accessed in February 2022.

32. Zhang, L. L.; Lin, D. Z.; Sun, X. Y. Y.; Curth, U.; Drosten, C.; Sauerhering, L.; Becker, S.; Rox, K.; Hilgenfeld, R.; Science 2020, 368, 409.

33. DeLano, W.; The PyMOL Molecular Graphics System; DeLano Scientific, USA, 2002.

34. Zhao, S. X.; Neves, M. G. P. M. S.; Tomé, A. C.; Silva, A. M. S.; Cavaleiro, J. A. S.; Sinclair, P. J.; Domingues, M. R. M.; Correia A. J. F.; Tetrahedron Lett. 2005, 46, 2189.

Submitted: December 13, 2021

Published online: February 21, 2022 